\title{
Gendered Parenting influence on Children's Socialization to Gender Stereotype in Marital life
}

\author{
Nisrutha Dulla \& Sugyanta Priyadarshini \\ ${ }^{1,2}$ School of Humanities, KIIT Deemed to be University, Bhubaneswar, India \\ 'nisrutha@gmail.com, 2sugyanta.priyadarshini@kiit.ac.in \\ ${ }^{1}$ ORCID: oooo-0003-0365-8281. ${ }^{2}$ ORCID: oooo-0001-7660-6162
}

\begin{abstract}
This research work draws attention towards heated debate on transfer of gender biased ideology to generations embedding from gendered parenting. Gendered parenting has the potential to be a breeding ground for fueling the belief of gender stereotyping in the minds of their offsprings. This notion of gender stereotyping has created a picture in the heads of the descendants regarding the fixed gender roles which develops gendered socialization in governing the social world from the lens of gender biasness. The objective of the study is to examine empirically the impact of gendered parenting on gendered socialization in their children's marital life. The study adopts thirty-two-items scale devised by Brogan \& Kutner (1976) and eightitems scale under Gender Role Stereotype Scale (2012) by taking into consideration a sample size of eight hundred respondents comprising of highly educated married professionals and their parents. The findings revealed that children have rightly perceived their parent's act of gender stereotype in their childhood. Consequently, despite being highly educated, the act of gender stereotyping continues in their married life as they burgeoned under the reflection of gendered parenting. Furthermore, it is also interpreted in the analysis that the female respondents are adversely affected by the pervasive bias and prejudices of gender stereotype in professional life in comparison to the male respondents. The study makes efforts to enhance the understanding of the community of parents to limit the transmission of gendered ideology to their next generations, thereby, progressing towards egalitarian society.
\end{abstract}

Keywords: Gender, Gendered Parenting, Gender Stereotype, Gender Socialization, Marriage, Couples.

\section{Introduction}

In this paradoxical world, where the human civilization presumes to be in resonance with the pellmell alacritous and evolving society, it is still shrouded with the invisible cloak of Gender stereotyping. Gender stereotyping is the practice of ascribing to all the individual man or woman specific attributes based on preconceived prejudices. Customarily, it is believed that female stereotypic role is limited to domestic frontiers and are called as 'caregivers' for being loving, caring and affectionate towards their family and their children whereas, male stereotypic role is to stand as a bulwark for the family and fulfil their needs as they are the sole 'breadwinners'. This societal norm is so deeply entrenched that it is considered to be quotidian. However, the so believed quotidian tradition of Gender stereotyping came into limelight as a human civilization metamorphosed with the transmogrifying society. By way of people's social analysis grew finer, their social intervention got finely tuned and they became aware of the biased and judgmental ways in which society slots people into two categories by their respective gender. Therefore, what has

(c) AesthetixMS 2021. This Open Access article is published under a Creative Commons Attribution Non-Commercial 4.0 International License (http://creativecommons.org/licenses/by-nc/4.o/), which permits non-commercial re-use, distribution, and reproduction in any medium, provided the original work is properly cited. For citation use the DOI. For commercial re-use, please contact editor@rupkatha.com. 
been hitherto implicit got explicit. Even if, the term has become explicit, people have not apprehended the gravity of the matter. Intriguingly, gender stereotyping is so deeply rooted and branched in Indian society that when a child grows in such circumstances, it dangles with it without any misconstrue. The child finds it very mundane for their mother to carry out all household chores without any complain and being loving, caring and compassionate to everyone whereas, they believe their father to be the sole bread earner and decision maker in the family. Even after, the child excels and becomes oofy, this bigoted and biased outlook of gender stereotyping still persists in their mind, thereby they behave and impose the same conviction on their spouse and is further passed to the future generation. As a result, the upcoming generations gets grappled into the morass of gender stereotyping.

\section{Review of Literature on key themes of the Research Issue}

\subsection{Understanding the concept of Gender and Gender Stereotype}

In order to collect a pool of primary data to explore the influence of parental and spouse strong believe on gender stereotype in field of education, carrier and family life of their respective offspring and partner, a systematic review of literature is conducted across the lifespan and throughout historical eras. Scholars conceptualize 'Gender' as a multilevel institutionalized arrangement of social practices which shelters cultural beliefs, distribution of resources at macro level, behavioral pattern at the interactional level and assigned role and identities at micro level (Ridgeway and Correll, 2004). Per the view of (Gupta and Turban, 2012), the concept of 'Gender' construe the masculine and feminine as diverse in socially relevant ways which potentially reinforces inequality in the society. Additionally, stereotyping the concept of 'Gender' fuel the flame of gender biasness by formulating preconceived ideas whereby females and males are arbitrarily assigned attributes and roles determined and limited by their gender. In other words, 'Gender Stereotype' is the widely hold notions of the society on traits and roles that are ought to be possessed by men and women (Heilman, 2001). Further, gender roles fixed by the society creates a 'picture in the heads' for making biased judgement and assessment regarding gender (Ashmore and Del Boca, 1979). This biased picturization in minds of society decides the male-typed and female-typed jobs (Cohen and Huffman, 2003) whereby, former attracts higher wages than the latter (Nosek et al.2002).

\subsection{Gender stereotyping in Indian Culture}

India is a nation of customs, norms, values, taboos and culture. However, the culture has been used as an excuse by the Indian society to create a line of discrimination between men and women. Even if the culture is supposed to be practiced by the whole society but unfortunately, women are often expected more than men to obey the cultural practices and gender stereotypes. The act of gender stereotyping is deeply-rooted in the veins of Indian society. Gender roles ingrained within Indian culture is firmly demarcated and distinguished (Koenig and Eagly, 2014). Since ages, men are expected to be firm and decisive whereas, women are to be subtle and placid. The patriarchal facet of Indian society and culture provides males in the family the upper hand in decision making, breadwinning and shielding the family (Lippa et al., 2014). This inclination for masculinity imbue stark differences in gender roles and restricts women to domestic frontiers of home thereby focusing on building quality in relationship and family life (Adom \& Anambane, 2019). These dual

tenets of social perception of contrasting distribution of men and women into social roles have been considered fundamental to gender stereotypes (Hentschel et al., 2019).

\subsection{Parental Influence on Children's Socialization to Gender Stereotype as a spouse}


In a society rife with gender stereotypes and imbalances, children often grow up learning to adopt gender roles which are mostly unfair to both sexes. While bridging the gap between childhood to adulthood, children come across several elements that influence their outlook and perception towards gender roles (Witt, 1997). However, their approach regarding gender stereotype is generally framed fore mostly in their homes and is further, reinforced through close observation and environmental stimulation in daily life via neighborhood and community attitude, school experience and television viewing regarding both sexes. However, the family has the effective potential in influencing the perception of their children's belief on gender stereotype by passing on, both overtly and covertly, their personal dogmas about gender role (Kirkwood, 2007). Parents solely uphold the primary responsibility of bending their children's perspective in a desirable direction by teaching and supervising them as they grow up (Maccoby, 200o). Parents, as a primary socializing agency pass on deep-rooted messages regarding their traditional outlook towards gender stereotype to their children, who in turn consider women responsible for household work and men responsible for breadwinning support (Miller \& Kaufman, 1996). Further, after entering into institution of marriage, they expect the same traditional perspective from their spouse which does not matter much if the partners practice the same standpoint on the role of husband and wife. Unfortunately, if either partner holds on an egalitarian role, they can have a hard time as the couple progress in their marriage (Pascale \& Primavera, 2020).

\subsection{Explaining Gender stereotyping in Education, Career Choice and Workplace}

The education institution is the subsystem of the society, and thus reflects the beliefs and values of the society. Gender discrimination is a key factor in formulating and practicing gender biased norms and curricula in school. An analysis of textbooks centering on the implicit communication of gender role in pictures contained in it was conducted by Finsterwald and Ziegler (2007). It was observed that 300 pictures depicted the ideas of gender stereotype in 28 textbooks ranging from Grade 1 to Grade 4. It was further found that adult male characters are presented more frequently than adult female characters in the course books. However, the adult male characters are projected as more individualistic, competitive and daring in comparison to adult female characters. In terms of child characters, girls are depicted as more passive and compliant in comparison to boys. Thus, it was evident enough that teaching materials not just upkeep student learning but also convey socially shared cultural knowledge, such as stereotypes (Hintermann, Markom, Üllen, \& Weinhäupl, 2014; Moser, Hannover, \& Becker, 2013). Further, in most of the societies it is believed that males are educated to earn a living while females are educated either to get good marriage prospect or to teach values to off springs. This is quite vigilant when female predominate in courses in education, health care as well as social sciences whereas males be in the majority in the courses in science, technology engineering and mathematics (STEM) (Kirkwood, 2007). This persisting male-female gap in accessing educational opportunities contribute to lack of improvement in women's socio-economic status.

In domestic frontiers, women perform several household activities and most importantly play the role of care-taker. Even if they are allowed to work but it comes with certain conditions such as limited working hours, distance from home, salary range, proper transportation to workplace and proper replacement arrangement for care giving to the family. Unfortunately, after employment, attrition rate is much high because they have to look into spouse, children and elderly care, and relocation of husband and in laws to another place at a priority basis. It is often observed that majority women are allowed to seek employment when there is a financial crunch in the family. Once, the catastrophe has settled down and the basic needs are fulfilled, then the family forces the woman to quit the job and take adequate care of the family (Valliami \& Savithiri, 2020). 
It is analyzed that women carryout two-thirds of world's work and receive merely ten percent of the world's income and own just one percent of the means of production (Singha, 2013). Although, it is visible that women have progressed in the workplace to a significant extent, unfortunately the patriarchal society does not leave a stone unturned to drag them down by encumbering their shoulders with familiar responsibilities. On this basis, job sector is divided into 'male' or 'female' specific occupation. Less demanding and low paid jobs are left for women where as men compete for well paid jobs. Reason being, women are concluded in the thoughts to be efficient housewife and is still believed that they can't be proved to be proficient employee as their familiar responsibility will outweigh their professionalism (Lips \& Lawson, 2009). This kind of biased segregation reduces the efficiency and this is the point where gender stereotype is evident. It is sad to note that in the workplace, majority of women are employed people-oriented, service occupations rather than things-oriented, competitive occupations, which have traditionally been occupied by men (Lippa et al., 2014). This antagonistic division of men and women into social roles and the inferences that stimulates about what men and women are like, gives rise to the concept of Gender stereotype. (Koenig and Eagly, 2014).

\section{Methodology}

The study focused on the quantitative approach for data collection and data analysis in order to acquire qualitative results regarding the extent of practice of gender stereotyping in the contemporary society. The sample size for the survey is 800 which is collected through random and then eventually through snowball sampling. Data was collected from 400 highly educated (Master Degree in specific domain) married professionals aging 28-55 years. Responses from a wide range of doctors, academicians, industrialists, and lawyers were used to seek a generalized perception towards gender stereotyping of highly educated masses in Bhubaneswar, India. Bhubaneswar is selected for data collection in order to figure out the outlook of masses regarding gender roles in the fastest growing smart city of India. However, the sample included equal proportion of men and women (200 each) and their respective parents. The paper is simplified by segregating the sample into two groups: Group I includes 200 married men and 200 married women working in organized sectors and Group II includes 400 parents of the above mentioned 400 highly educated personnel. The respondents of group I are selected through random sampling and respondents of group II are accessed through snowball sampling with the help of the respondents of Group I. It took approximately 11 months for data collection to meet the estimated sample size. In the first phase of data collection, respondents of group 1 were provided with a structured questionnaire dealing with their perception of gender stereotype of their parents in their childhood and they were also asked about the negative effects of gender stereotype in their life after marriage. In the second phase of data collection, respondents of group 2 were provided with a set of questionnaire which will let the investigator analyze how far parents have grown up their child or discriminated their children on the basis of gender role and stereotype. However, respondents were not informed about the actual purpose of data in order to avoid biased responses. Further, a gap of 2 months was intentionally kept in between data collection of Group 1 and Group 2 in order to avoid the influence of group 1 over group 2.

The study required an instrument to measure gender role or stereotype orientation for better analysis. Therefore, the investigator went through several instruments but was highly impressed with the scope of item content and reliability-validity of the tool developed by Brogan and Kutner (1976) and Mills, Huffman \& Culbertson (2012). Mothers and fathers were provided with a 32 set of questions in a questionnaire (Brogan \& Kutner, 1976) dealing with their perception regarding 
gender stereotype. Participants were asked to respond to each item by picking up one of the six alternatives ranging from "strongly agree", "moderately agree", "agree slightly more than disagree", "disagree slightly more than agree", "moderately disagree", and "strongly disagree". The score ranges from 32 to 192. The lower the score, more traditional the respondent's gender stereotype perception. Further, Gender role Stereotype scale is used in the paper to find out the attitude of spouses towards each other with only eight items. This tool is preferred over other tools because it includes the items that are easily understandable, cross-culturally appropriate, and modern (Mills, Huffman \& Culbertson, 2012).

\section{Purpose of the study}

1. To evaluate whether Group 1 respondents have come across the gendered parenting in their early childhood.

2. To explore which of the either gender is more negatively impacted by the pervasive bias and prejudices of gender stereotype.

3. To reconnoiter whether the believes of gender stereotyping is transferred to future generation.

\section{Discussion}

5.1 A comparative study of Perception of Group 1 respondents regarding Gendered parenting experiences in their childhood with outlook of Group II regarding Gender Stereotyping

Prior research has demonstrated that the general parenting practices in early childhood including being warm, sensitive and practicing parental control come up with minimal differences in the treatment of the infant based on gender. However, the differences are visible in implicit parenting practices. Soon, when the child grows up as a boy or girl, parents form expectations regarding the child's interest, behavior and skills and, thereby expectations appear in gendered parenting practices (Mesman \& Groeneveld, 2018). Further, children's psychological growth is a replica of their parental role (Harris, 1998). The influences of gendered socialization by parents in early childhood leaves a significant mark on the child psychology resulting which they govern the social world accordingly. In the current study, perception of Group 1 respondents about their parent's gender stereotype ideas and believes are recorded to find out to what extent they have come across gender schemas that may influence their interests, and social behavior. The analysis is conducted by taking into account 32 questions under 4 major headings (8 each) such as Education, Chore works, Feminine Courses and Career Opportunities. Responses from both Group I and Group II is taken into account to picturize how far perception of Group 1 respondents regarding Gendered parenting experiences in their childhood is similar with the outlook of Group II regarding Gender Stereotyping. These questions are categorized under these 4 captions as Education, Feminine Courses and Career Opportunities are mostly related to situational factors corresponding to the respondent and additionally, to focus on domestic frontiers, Household work is taken into consideration. The tool developed by Brogan and Kutner (1976) is used in the study considering 32 items that were devised to sample the following content area ranging the scores from 32 to 192. Under the category of education, respondents were asked their views on statements such as "Education is important for both sons and daughters but is more important for a son", Financial 
support to male child should be given much preference in comparison to female for education" to which they respond within a range from 1 to 6 ("1=strongly agree", "2=moderately agree", "3=agree slightly more than disagree", "4=disagree slightly more than agree", "5=moderately disagree", and "6=strongly disagree"). Similarly, under the category of Chore works, Feminine Courses and Career Opportunities, respondents were asked their views on statements which are mentioned in the Appendix A.
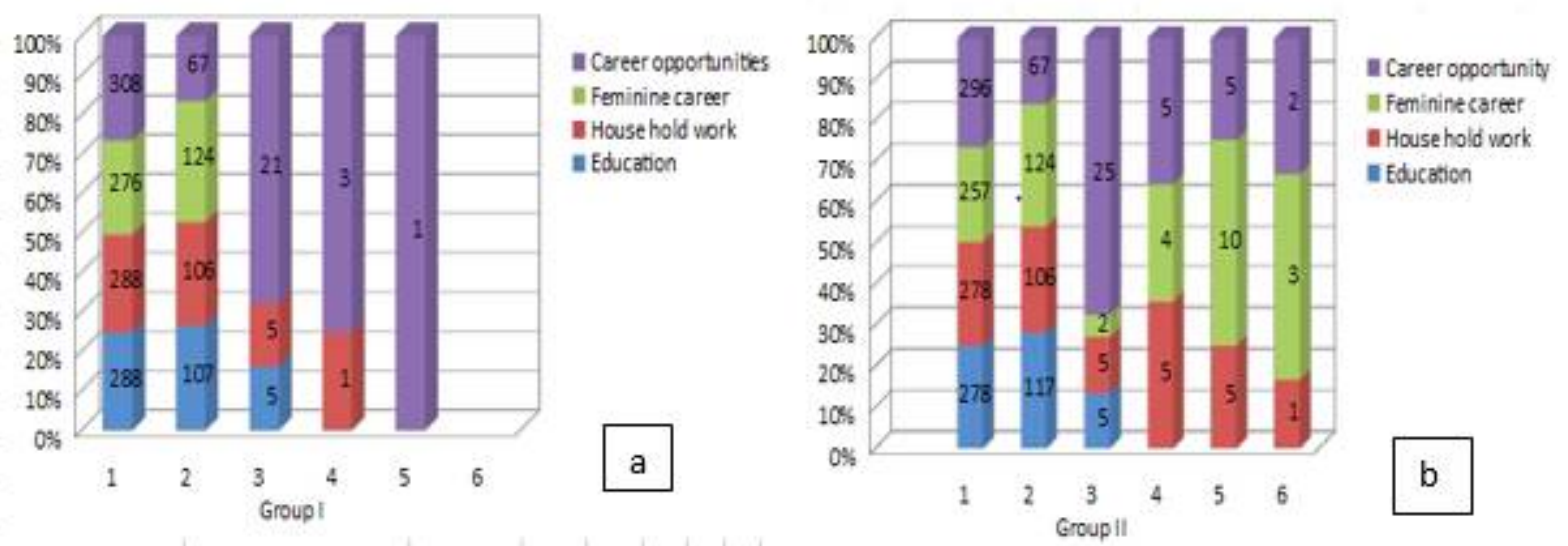

Figure 1. A comparison of perception of Group I on Gendered Parenting of Group II

The Figure 1 represents the perception of Group I on gendered parenting of Group II and the views of Group II regarding gender stereotyping. It was observed that, Group I stated that their parents strongly believed in gender stereotyping in field of education, House hold work, feminine career and career opportunities to an extent of $72 \%, 72 \%, 69 \%, 77 \%$ respectively. Their perception regarding it was approximately correct when it was observed that parents strongly believed in gender stereotyping in education stream House hold work, feminine career and career opportunities to an extent of $69.5 \%, 69.5 \%, 64.2 \%$ and $74 \%$ respectively. It was found that $97.75 \%$ of Group I and $95.17 \%$ of Group II responses fall under the range of 32 to 64 which represented strong traditional outlook towards gender stereotyping by parents.

5.1.1 Checking the relation between parent gender stereotype and child's perception of parent's gender stereotype

The responses of Group I are considered as dependent variable and responses of Group II is considered as independent variable, in order to interpret whether group I had perceived rightly the approach of group II regarding Gender Stereotype.

Tableı Regression analysis of Group I perception of Gendered parenting of Group II respondents

\begin{tabular}{|l|l|l|l|l|}
\hline Sl.No. & Dependent & Independent & p-value & Result \\
\hline 1. & G1_Gender stereotyped & G2_gender stereotyped & 0.001 & Significant \\
\hline 2. & G1_Not stereotyped & G2_Not stereotyped & 0.001 & Significant \\
\hline
\end{tabular}

Correlation of Group I and Group II have been tested and the result is significant ( $\mathrm{p}=0.001)$. It can be inferred that in model 1, the Group I who considered Group II as gendered stereotyped were correct in their approach and in model 2, the Group I who considered Group II as not gendered stereotyped were also correct in their approach. Thus, it can be concluded that what Group I 
respondents have observed during their childhood is what their parents were from the lens of Gender roles and stereotypes.

\subsection{A comparative analysis of the constraints faced by male and female respondents in career development}

In India, gender inequality results in unequal opportunities, and while it impacts both the genders, statistically it is girls/women who are more disadvantaged in comparison to boys/men. In India girls and boys experience adolescence differently. On one hand, men tend to experience greater freedom whereas, on the other hand, women have to face extensive restrains on their ability to express, make decisions about their career and nature of job keeping in mind their early marriage, social relationships and family responsibilities. However, there are vivid challenges faced by women while progressing forward in their career including domestic chores, family responsibilities, indifferent attitude of family members at home regarding their career making, provision of limited finance towards their education, lack of effective mentoring, occupational inequalities and time constraints in returning home. These barriers impose impediments in the career development of women. The researcher's intention is to know which group of gender have faced much difficulties in their career aspects, thereby taking into account a nominal scale of measurement ( $1=\mathrm{Yes}, 2=\mathrm{No})$. General questions were asked to 200 male respondents and 200 female respondents on financial issues, timing constraints, family responsibility and occupational inequalities such as "Have you sacrificed your choice of education based on financial issues?", "Did you ever face restrictions on working or education based on timings constraints?", "Did you have ever sacrifice your choice of education or career opportunities due to family responsibilities?", "Have you faced any inequality of salary or promotions in your job?". The data collected from the respondents picturized the unequal opportunities and extensive limitations in the career development for women and a very negligible barrier in career development of men. It is observed from figure 2 that $50 \%$ of female respondents faced occupational inequality in their work place such as inequality in providing credits, leadership posts, promotions, salary hikes, appraisals with a perspective that their family responsibility would someday or other outweigh their professionalism whereas, only $2.5 \%$ men have faced occupational inequality stating that the the lady charm has outweighed their talent and skill for promotion and appraisals. Women are considered as the responsible for maintaining happy homes by taking good care of family members, child and their spouse. It becomes very difficult for working woman to maintain work life balance which further creates certain compromises in career development. Further, $82.5 \%$ female have faced the burden of family responsibilities obstructing their way to success in career development whereas $5 \%$ male respondents have realized that their problems in family life but not the family responsibility is hindering their progress. Additionally, working hours and night shift jobs creates troubles for $87.50 \%$ of women in career advancement where no male respondent considers time constraint as one of the obstruction in career development. Most of the times, family members discourage women for employment opportunities and encourage them to indulge themselves in household work. Elderly members of the household possess the viewpoint that women are meant to stay at home and remain caregivers. Therefore, huge investment on their education is considered vague. Thus, lack of financial support for education limited them from developing effective skills for their career advancement. 90\% of female respondents have faced financial constraints in their life while accessing education and opting for expensive and exclusive courses for career development whereas, $15 \%$ male respondents have also faced financial constraints because of their poor economic condition of their family. 


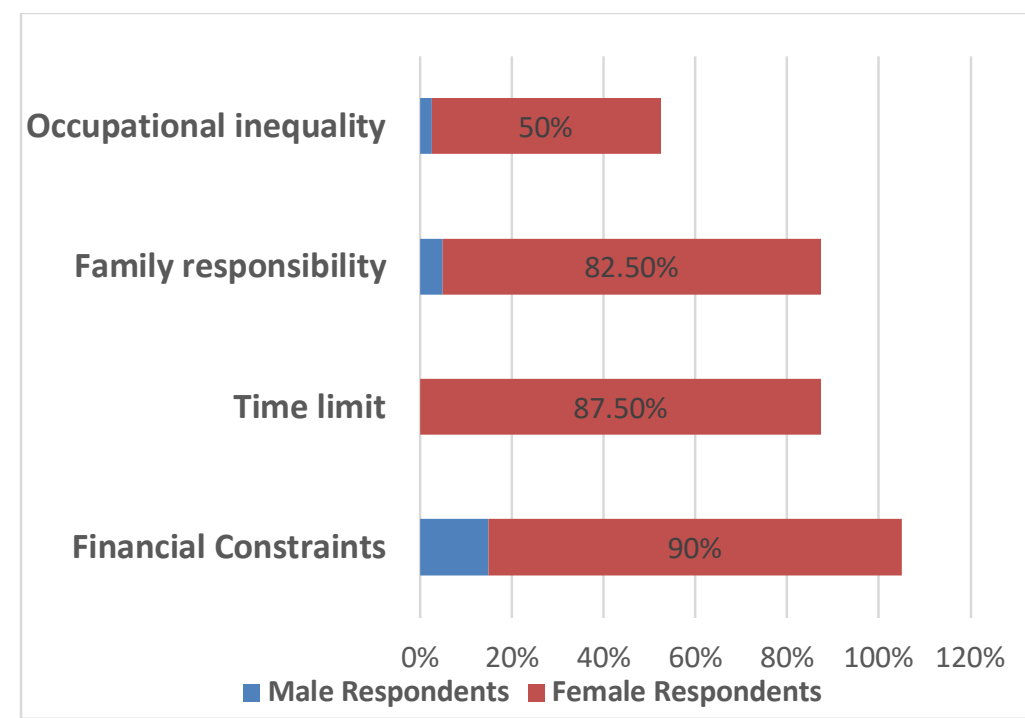

Figure 2 Constraints faced by Group I respondents in career development

\subsection{Evaluating the transfer of the idea of gender stereotyping to Future Generation.}

Parents may not have gendered parenting goals, but unconsciously, they convey the message of gender stereotyping through their action and practices. Children are curious and fast learners, thereby constantly absorb the actions and behavior from their parents primarily and later on from the surroundings. What a child learns and understands, depends on what parents had shown them during their development stage. One of the very influential thing of a child which it learns from a parent is understanding the gender roles. Interesting studies of Blomen and Stancenelli in 2014 have revealed certain outcomes like if a father is a bread winner, it negatively affected the house hold working hours of a mother. It conveys a message to the child that father must earn and mother should do house hold work. It is not always that what we communicate will only be heard, our actions also speak. Parent's roles as a male and female are identified by child, so similar roles might be replicated by them in their space of marital relationships with their respective partner. The strict adherence to traditional gender roles gets imprinted in the brain of children who considered gender socialization very explicit.

Men are generally observed to exercise more power than women within the marriage relationship which is gradually understood by their child and the same is carried forward when the child grows up and enters into the institution of marriage. On one hand, expectation of the male child from their spouse remains the same which they have observed from their father towards their mother and on the other hand, the expectations of a female child from their spouse remains the same which they have observed from their mother towards their father. Negative effects of gender stereotype adversely affect relation with the spouse. Previous researchers have found that egalitarian couples who share their duties equally are happier couples (Aloni, 2013) than the people who share responsibilities based on predetermined gender roles. However, in this study, it is evaluated how far the idea of gender stereotype is transferred from parents to their children in relation to their respective spouse. Thus, in this study, Gender Role Stereotype Scale is practiced by taking 8 items into account, out of which 5 referred to male role items (Hard tasks of gardening, purchasing expense, Bill payment, servicing of vehicles and earnings) and 3 referred to female role items (Childcare, cooking, cleaning). The responses are recorded under 5point Likert scale ranging from 1 to $5(1=$ 'Should always be done by men', $2=$ 'Should usually be done by men', $3=$ 'Equally shared', ' $4=$ 'Should always be done by women', $5=$ 'Should usually be done by women'). The same set of 
eight questions is asked to both Group I and Group II. The 8 items are mentioned in the Appendix $\mathrm{B}$ in the end of the paper.

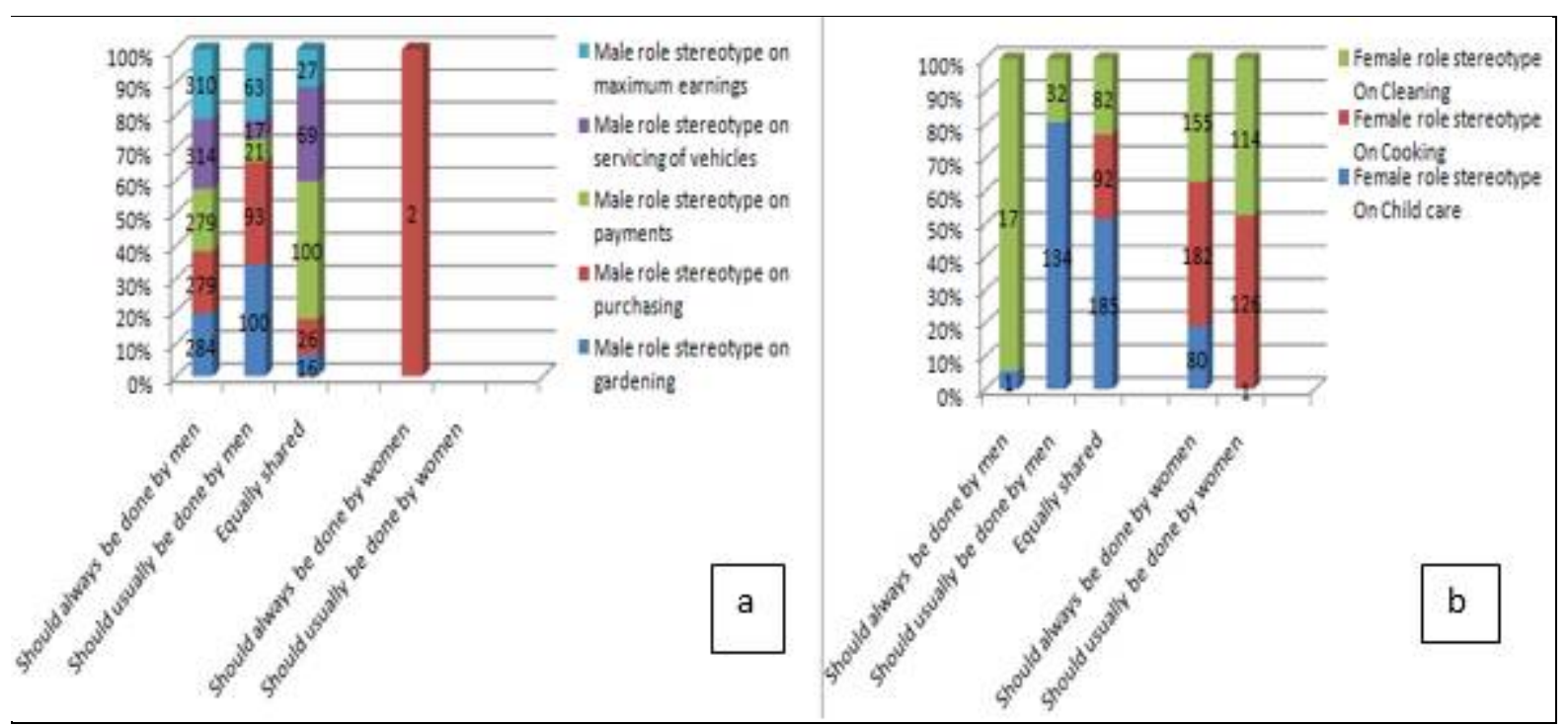

Figure 3 a) Measuring the male roles of Group I respondents b) Measuring the female roles of Group I respondents

Figure za interprets that 384 respondents of Group I have opted for dominance of husband for hard task of Gardening out of which 284 stated that the task should always be done by the husband and 100 stated that the same task should be usually done by the husband; 372 have opted for dominance of husband decision in purchasing of any commodity, out of which 279 stated that the task should always be done by the husband and 93 stated that the same task should be usually done by the husband; 301 have opted for dominance of husband in payments of bills, out of which 279 stated that the task should always be done by the husband and 21 stated that the same task should be usually done by the husband; 331 have opted for dominance of husband on servicing of vehicles, out of which 314 stated that the task should always be done by the husband and 17 stated that the same task should be usually done by the husband 373 have opted for dominance of husband in maximum contribution to family income, out of which 310 stated that the task should always be done by the husband and 63 stated that the same task should be usually done by the husband.

Out of the data, 16 respondents are sharing equal responsibilities in gardening with their spouse, 26 respondents are sharing equal responsibilities in decision making of the purchase of any commodity with their spouse, 100 respondents are sharing equal responsibilities for payments with their spouse and 69 respondents are sharing equal responsibilities in servicing of vehicles with their spouse, 27 respondents are sharing equal responsibilities in contributing equal amount to family with their spouse. It is also observed 2 respondents of Group I have opted for the dominance of wives in decision in purchasing of any commodity; thereby breaking the glass ceiling of gender stereotype perception.

Figure $3 \mathrm{~b}$ interprets that 80 respondents of Group I have opted for dominance of wives in child care whereas 185 respondents equally shared the responsibility in child care. 135 respondents of Group I have opted for dominance of husband for childcare out of which 1 stated that the task should always be done by the husband and 134 stated that the same task should be usually done by the husband. 308 respondents of Group I have opted for dominance of wives for cooking out of which 182 stated that the task should always be done by the wives and 126 considered that the same task should be 
usually done by the wives. Further, 92 respondents shared equal responsibility of cooking with their spouse. 269 respondents of Group I have opted for dominance of wives for cleaning activities out of which 155 stated that the task should always be done by the wives and 114 stated that the same task should be usually done by the wives. Additionally, 82 respondents shared equal responsibility of cleaning activity with their spouse. 49 respondents have successfully broken the glass ceiling by opting the dominance of husbands in doing the cleaning activities.

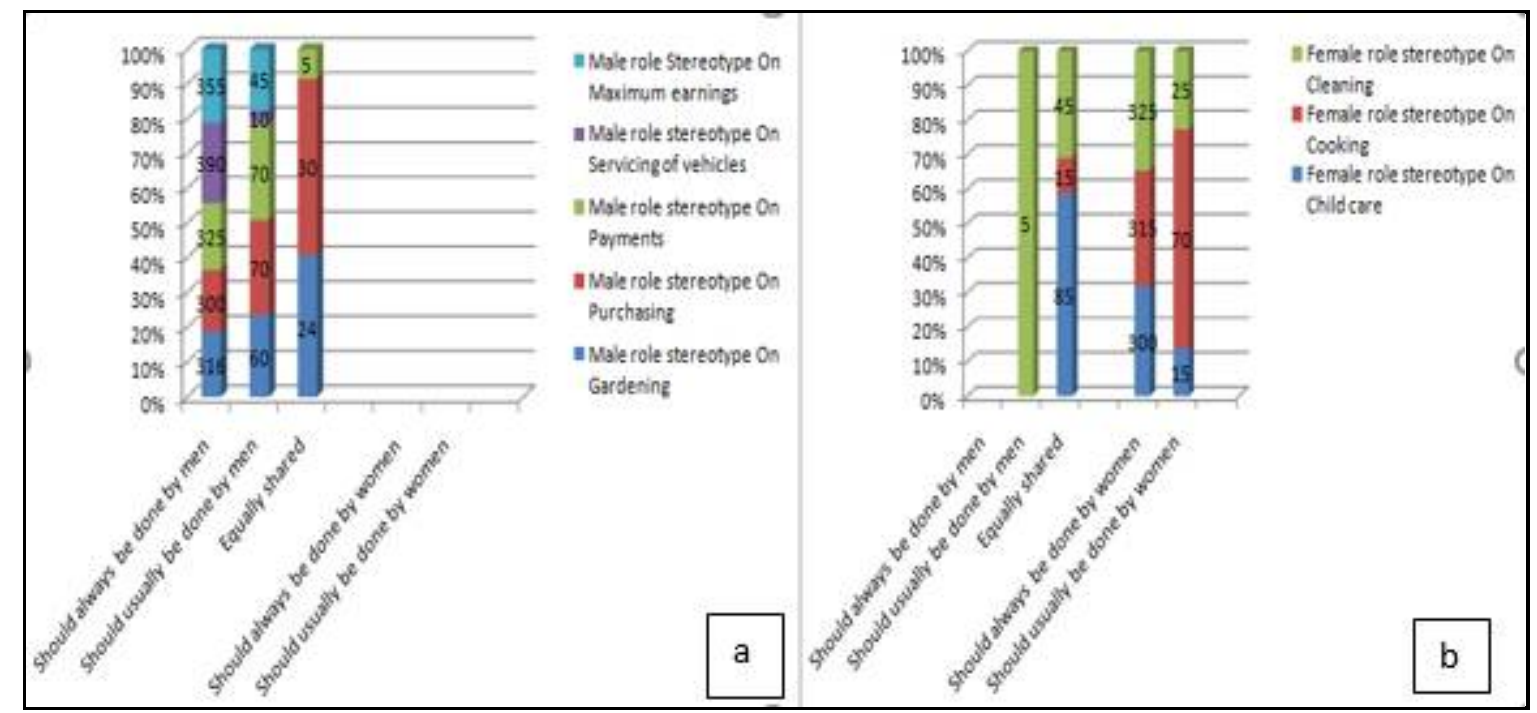

Figure 4 a) Measuring the male roles of Group II respondents b) Measuring the female roles of Group II respondents

Figure 4a interprets that 376 respondents of Group II have opted for dominance of husband for hard task of Gardening out of which 316 stated that the task should always be done by the husband and 60 stated that the same task should be usually done by the husband; 370 have opted for dominance of husband decision in purchasing of any commodity, out of which 300 consider that the task should always be done by the husband and 70 stated that the same task should be usually done by the husband; 395 have opted for dominance of husband in payments of bills, out of which 325 stated that the task should always be done by the husband and 70 stated that the same task should be usually done by the husband; 400 have opted for dominance of husband on servicing of vehicles, out of which 390 stated that the task should always be done by the husband and 10 stated that the same task should be usually done by the husband 400 have opted for dominance of husband in maximum contribution to family income, out of which 355 stated that the task should always be done by the husband and 45 stated that the same task should be usually done by the husband.

Out of the data, 24 respondents are sharing equal responsibilities in gardening with their spouse, 30 respondents are sharing equal responsibilities in decision making of the purchase of any commodity with their spouse, 5 respondents are sharing equal responsibilities for payments with their spouse and no respondents are sharing equal responsibilities in servicing of vehicles with their spouse and no respondents are sharing equal responsibilities in contributing equal amount to family with their spouse.

Figure $4 \mathrm{~b}$ interprets that 315 respondents of Group I have opted for dominance of wives in child care, out of which 300 stated that the task should always be done by the wives and 15 stated that the same task should be usually done by the husband whereas 85 respondents equally shared the responsibility in child care. 385 respondents of Group I have opted for dominance of wives for 
cooking out of which 315 consider that the task should always be done by the wives and 70 considered that the same task should be usually done by the wives. Further, 15 respondents shared equal responsibility of cooking with their spouse. 350 respondents of Group I have opted for dominance of wives for cleaning activities out of which 325 stated that the task should always be done by the wives and 25 stated that the same task should be usually done by the wives. Additionally, 45 respondents shared equal responsibility of cleaning activity with their spouse. 5 respondents have successfully broken the glass ceiling by opting the dominance of husbands in doing the cleaning activities.

From Figure $3 \mathrm{a}$ and b \& Figure $4 \mathrm{a}$ and b, It was observed that, the $96 \%$ respondents of Group I and 94\% of group II opined that Gardening is a male dominated task; 93\% respondents of Group I and $92.5 \%$ of group II opined that decision on purchasing a commodity is a male dominated task; $75 \%$ respondents of Group I and $98.75 \%$ of group II opined that payments of bills is a male dominated task; $82.75 \%$ respondents of Group I and $100 \%$ of group II opined that servicing of vehicles is a male dominated task; $93.25 \%$ respondents of Group I and 100\% of group II opined that responsibility of earning maximum income for family is a male dominated task. Further, it was also observed that, $20.25 \%$ respondents of Group I and $78.75 \%$ of group II opined that Childcare is a female dominated task; $77 \%$ respondents of Group I and $96.25 \%$ of group II opined that Cooking is a female dominated task; $67.25 \%$ respondents of Group I and $87.5 \%$ of group II opined that Cleaning is a female dominated task.

\subsubsection{Checking the influence of parent's gender role as a spouse role on child's gender role as a spouse}

From, the analysis done in the Table 2, the influence of parent's gender role as a spouse role on child's gender role as a spouse is verified through regression analysis.

Table 2 Regression analysis of Group I and Group II respondents on spouse gender stereotype

\begin{tabular}{|l|l|l|l|l|}
\hline Sl.No. & Dependent & Independent & p-value & Result \\
\hline 1 & G1_male role stereotype & G2_male role stereotype & 0.006 & Significant \\
\hline 2 & G1_female role stereotype & G2_female role stereotype & 0.003 & Significant \\
\hline 3 & G1_No stereotype & G2_No stereotype & 0.397 & Not significant \\
\hline
\end{tabular}

The responses of Group I are considered as dependent variable and responses of Group II is considered as independent variable, in order to interpret to what extent the gender role in marriage of Group II has influenced the gender role in marriage of Group I. From the results it can be inferred that in Model 1, Group I male role stereotype has been influenced by Group II male role stereotype as the result is significant ( $\mathrm{p}=0.006$ ). In model 2, Group I female role stereotype has been influenced by Group II female role stereotype as the result is significant ( $\mathrm{p}=0.003)$. Group I not stereotyped has not been influenced by Group II as the result is insignificant $(\mathrm{p}=0.397)$.

\section{Results}


1. From the Figure 1, it can be easily interpreted that children have perceived their parent's stereotype rightly. What the child observes in childhood it gets registered in the mind rigidly. Through statistical inferences from Table 1 as the correlation is significant between Group II and Group I respondent, it can be conferred that Group I respondents had perceived the stereotype attitude of parent's in the similar way as their parents.

2. From Figure 2, it can be inferred that female respondents have faced more negative constraints in their life regarding financial restraints, time limit, family responsibilities and occupational inequalities.

3. From Figure $3 \mathrm{a}$ and b, $4 \mathrm{a}$ and $\mathrm{b}$ and Table 2, it replicates that gender role in marriage of Group II has influenced the gender role in marriage of Group I, thereby transferring the ideas and believes of gender stereotype to future generation. It is observed by comparing the parent's gender role as a spouse and child's gender role as a spouse. Through statistical inference of regression analysis, it is hereby confirmed that gender role in marriage of parents has influenced the gender role in marriage of their children.

\section{Societal Implication of the Current Research}

The voguish, sassy, spiffy and so-called progressive society has been engaged in polishing and decorating the societal cage in which every individual has imprisoned themselves along with their obsolete and antediluvian thoughts. Gender stereotyping is one of such ant wacky societal norm which has been deeply engrained. No doubt,it is arduous to break the cage and change the outworn prejudices. Nevertheless, it is of the essence as amputation of Gender stereotyping can annihilate gender parenting and bring forth an egalitarian society. This study bespeaks of the visibly invisible malady of gender stereotyping that has poisoned and crippled the society. It also insights the anachronistic mindset of people who themselves are a victim of gender parenting and are now passing it to future generation. In gender parenting, where children are parented based on stereotype, the child's talent might get wasted if they are not allowed to spread their wings and pursue the career of their own choice. Diverging from monotonous gender parenting and allowing children to do what they wish is definitely difficult, unacceptable and obnoxious for the society. But this onerous and gutsy diversion from gender parenting boosts talent and abilities of a child and indemnifies a flamboyant future and desired lifestyle. The current study is an addition to the limited research on exigency of rich profusion of social implication of eradicating gender parenting and gender stereotype to march forward in the trajectory of egalitarianism gender biased society.

\section{Conclusion}

After a coon's age of inexorable tribulation, torment and torture, women finally gathered courage to give the clarion call for their emancipation. Nevertheless, even after years of feuding, they failed to achieve de-facto gender equality in the society. The paramount stumbling hindrance in the trajectory of achieving gender equality is Gender stereotype. Gender stereotype is so deeply entrenched in the Indian society, that it has hermetically grasped the human civilization for ages and now seems to be very customary. Gender stereotype is imposed since babyhood through outfit, interactions, stories, books and future aims and aspirations by their parents. Consequently, Gender stereotype is transferred from infancy to childhood, and then to adolescence primarily through gendered parenting, and then through near and dear ones, media and social sites. Just like an inherited disease, gender stereotyping is passed down to generation being unnoticed. The 
ambivalent line of gender stereotyping drawn by our forefathers has stereotyped children based on their gender and when they grow up they pass it down to next generation. As the tiny seed of implanted gender stereotype has grown and ramified into a giant-sequoia, bedeviling the society; it is cumbersome to uproot it suddenly. It requires the commingled efforts of every section of society. Because women are the only oppressed group that lives in an intimate association with their oppressors, hence they must need to break the monotony of gender stereotyping as a mother, daughter and a wife. It can be done by encouraging cross gender activities. Textbooks, teacher training programs must be periodically reviewed to ensure that gender stereotype are not perpetuated. More importance should be given on career counselling so that school girls can know the plethora of career options present before them. More positive efforts are needed to amplify the gender mainstreaming process throughout the education system. Every person who encompasses child education should have indoctrination of principle of gender equality such that gender stereotyping can be discouraged. More demarche should be undertaken to promote and encourage women incorporation in same field. Additionally, research must be done on principles of gender stereotyping to create awareness in the society. International organizations and NGOs should come forward to advice the government to inculcate proposals to modify the current education system that will have potential to meet the needs of both males and female. Annihilation of gender stereotyping might appear as a utopian thought for many, but it is possible with the coalesced efforts of each and every section of society. No doubt, one day an egalitarian, progressive and neoteric society free of gender stereotyping can be established.

\section{References}

Adom, K., \& Anambane, G. (2019). Understanding the role of culture and gender stereotypes in women entrepreneurship through the lens of the stereotype threat theory. Journal of Entrepreneurship in Emerging Economies, 12(1), 100-124. https://doi.org/10.1108/JEEE-07-2018-0070

Aloni, G., \& Syna Desivilya, H. (2013). Eve's emancipation or lingering subordination to Adam?: The effects of egalitarianism, asymmetrical contextual ambiguity and priming of gender stereotypes on couples' negotiation. International Journal of Conflict Management, 24(3), 284-306.

https://doi.org/10.1108/IJCMA-10-2011-0070

Ashmore, R.D. and Del Boca, F.K. (1979), "Sex stereotypes and implicit personality theory: toward a cognitive-social psychological conceptualization”, Sex Roles, Vol. 5 No. 2, pp. 219-248.

Bloemen, H. G., \& Stancanelli, E. G. F. (2014). Market hours, household work, child care, and wage rates of partners: an empirical analysis. Review of Economics of the Household, 12(1), 51-81. https://doi.org/10.1007/s11150-013-9219-4

Finsterwald, M., \& Ziegler A.(2007). Geschlechtsrollenstereotype in Schulbuchabbildungen der Grundschule [Gender stereotypes in illustrations of textbooks for primary school]. In P. Ludwig \& H. Ludwig (Eds.), Erwartungen in himmelblau und rosarot. Effekte, Determinanten und Konsequenzen von Geschlechterdifferenzen in der Schule [Expectations in blue and pink. Effects, determinants and consequences of gender differences in school] (pp. 117-142). Weinheim: Juventa.

Heilman, M.E. (2001), “Description and prescription: how gender stereotypes prevent women's ascent up the organizational ladder", Journal of Social Issues, Vol. 57 No. 4, pp. 657-674.

Hentschel, T., Heilman, M. E., \& Peus, C. V. (2019). The Multiple Dimensions of Gender Stereotypes: A Current Look at Men's and Women's Characterizations of Others and Themselves. Frontiers in Psychology, 10. https://doi.org/10.3389/fpsyg.2019.00011 
Hintermann, C., Markom, C., Üllen, S., \& Weinhäupl, H. (2014). Debating migration in textbooks and classrooms in Austria. Journal of Educational Media, Memory, and Society, 6, 79-106

Kirkwood, J. (2007). Igniting the entrepreneurial spirit: Is the role parents play gendered? International Journal of Entrepreneurial Behavior E Research, 13(1), 39-59. https://doi.org/10.1108/13552550710725174

Koenig, A. M., \& Eagly, A. H. (2014). Evidence for the social role theory of stereotype content: Observations of groups' roles shape stereotypes. Journal of Personality and Social Psychology, 107(3), 371392. https://doi.org/10.1037/aoo37215

Lippa, R. A., Preston, K., and Penner, J. (2014). Women's representation in 6o occupations from 1972 to 2010: more women in high-status jobs, few women in things-oriented jobs. PLoS One 9:e9596o. doi: 10.1371/journal.pone.0095960

Lips, H., \& Lawson, K. M. (2009). Work Values, Gender, and Expectations About Work Commitment and Pay: Laying the Groundwork for the "Motherhood Penalty"? Sex Roles 61(9):667-676

Maccoby, E. E. (200o). Parenting and its Effects on Children: On Reading and Misreading Behavior Genetics. Annual Review of Psychology, 51(1), 1-27. https://doi.org/10.1146/annurev.psych.51.1.1

Mesman, J., \& Groeneveld, M. G. (2018). Gendered Parenting in Early Childhood: Subtle But Unmistakable if You Know Where to Look. Child Development Perspectives, 12(1), 22-27. https://doi.org/10.1111/cdep.12250

Miller, B., \& Kaufman, J. E. (1996). Beyond gender stereotypes: Spouse caregivers of persons with Dementia. Journal of Aging Studies, 10(3), 189-204. https://doi.org/10.1016/So890-4065(96)900201

Moser, F., Hannover, B., \& Becker, J. (2013). Subtile und direkte Mechanismen der sozialen Konstruktion von Geschlecht in Schulbüchern. Vorstellung eines Kategoriensystems zur Analyse der Geschlechter(un)gerechtigkeit von Texten und Bildern [Subtle and direct mechanisms of social construction of gender in textbooks. Presentation of a category system for the analysis of gender (un)fairness of texts and pictures]. Gender, 3, 77-93.

Nosek, B.A., Banaji, M.R. and Greenwald, A.G. (2002), "Harvesting implicit group attitudes and beliefs from a demonstration web site”, Group Dynamics: Theory, Research, and Practice, Vol. 6 No. 1, p. 101.

Pascale, R., \& Primavera, L. (2020, January). How Do Gender Roles Impact Marriage? Psychology Today. https://www.psychologytoday.com/blog/so-happy-together/202001/how-do-gender-roles-impactmarriage

Ridgeway, C.L. and Correll, S.J. (2004), "Unpacking the gender system: a theoretical perspective on gender beliefs and social relations", Gender and Society, Vol. 18 No. 4, pp. 510-531.

Singha, S. (2013). Architecture for Rapid Change and Scarce Resources. Routledge

Valliami, A., \& Savithiri, D. (2020). The Problem of Unemployment among the Educated Women in Nagapattinam. International Journal of Advanced Engineering Research and Science, 7(4), 325-333. https://doi.org/10.22161/ijaers.74.41

Witt, S. D. (1997). Parental influence on children's socialization to gender roles. Adolescence, 32(126), 253259 . 


\section{Appendix A}

Group I Perception on Gendered parenting of Group II and Group II Gendered parenting

\begin{tabular}{|c|c|c|c|c|c|c|c|c|}
\hline $\begin{array}{l}\text { Item } \\
\text { Category }\end{array}$ & & Statement & $\begin{array}{l}\text { G1 } \\
32-64\end{array}$ & $\begin{array}{l}\text { G1 } \\
96-128\end{array}$ & $\begin{array}{l}\text { G1 } \\
160-192\end{array}$ & $\begin{array}{l}\text { G2 } \\
32-64\end{array}$ & $\begin{array}{l}\text { G2 } \\
96-128\end{array}$ & $\begin{array}{l}\text { G2 } \\
160-192\end{array}$ \\
\hline \multirow{11}{*}{ Education } & 1 & $\begin{array}{l}\text { Education is important } \\
\text { for both sons and } \\
\text { daughters but is more } \\
\text { important for a son. }\end{array}$ & \multirow{8}{*}{395} & \multirow{8}{*}{5} & \multirow{8}{*}{$* *$} & \multirow{8}{*}{390} & \multirow{8}{*}{10} & \multirow{11}{*}{$* *$} \\
\hline & 2 & $\begin{array}{l}\text { Young girls should only } \\
\text { opt for playing indoor } \\
\text { games in school }\end{array}$ & & & & & & \\
\hline & 3 & $\begin{array}{l}\text { Career oriented education } \\
\text { is much important for } \\
\text { boys than girls }\end{array}$ & & & & & & \\
\hline & 4 & $\begin{array}{l}\text { Financial support for male } \\
\text { child should be given } \\
\text { much preference }\end{array}$ & & & & & & \\
\hline & 5 & $\begin{array}{l}\text { Girls should not be too } \\
\text { competitive }\end{array}$ & & & & & & \\
\hline & 6 & $\begin{array}{l}\text { Girls should feel free to } \\
\text { participate in games }\end{array}$ & & & & & & \\
\hline & 7 & $\begin{array}{l}\text { Girls should also be given } \\
\text { similar independence as } \\
\text { boys }\end{array}$ & & & & & & \\
\hline & 8 & $\begin{array}{l}\text { The only reason girls need } \\
\text { career education is to } \\
\text { remain unmarried }\end{array}$ & & & & & & \\
\hline & 9 & $\begin{array}{l}\text { It's okay for children to } \\
\text { help around the house, } \\
\text { but I would not ask son to } \\
\text { dust the table }\end{array}$ & & & & & & \\
\hline & 10 & $\begin{array}{l}\text { The use of profane or } \\
\text { obscene language by a } \\
\text { woman is objectionable }\end{array}$ & & & & & & \\
\hline & 11 & $\begin{array}{l}\text { It is acceptable for boys } \\
\text { and girls to play with } \\
\text { "DOLLS" }\end{array}$ & & & & & & \\
\hline
\end{tabular}




\begin{tabular}{|c|c|c|c|c|c|c|c|c|}
\hline \multirow{5}{*}{ HouseHold } & 12 & $\begin{array}{l}\text { It is O.K. for a wife to } \\
\text { keep her own last name, } \\
\text { rather than take her } \\
\text { husband's last name }\end{array}$ & \multirow{5}{*}{394} & \multirow{5}{*}{6} & \multirow{5}{*}{$* *$} & \multirow{5}{*}{384} & \multirow{5}{*}{10} & \multirow{5}{*}{6} \\
\hline & 13 & $\begin{array}{l}\text { Girls should preferrably } \\
\text { wear traditional dresses }\end{array}$ & & & & & & \\
\hline & 14 & $\begin{array}{l}\text { The husband should take } \\
\text { primary responsibility for } \\
\text { major family decisions }\end{array}$ & & & & & & \\
\hline & 15 & $\begin{array}{l}\text { It is not a good idea for a } \\
\text { husband to stay home and } \\
\text { care for the children }\end{array}$ & & & & & & \\
\hline & 16 & $\begin{array}{l}\text { A women should devote } \\
\text { more time for family }\end{array}$ & & & & & & \\
\hline \multirow{7}{*}{$\begin{array}{l}\text { Feminine } \\
\text { career }\end{array}$} & 17 & $\begin{array}{l}\text { Girls should primarily be } \\
\text { encouraged to enter } \\
\text { "feminine career" }\end{array}$ & \multirow{7}{*}{400} & \multirow{7}{*}{$* *$} & \multirow{7}{*}{$* *$} & \multirow{7}{*}{381} & \multirow{7}{*}{6} & \multirow{7}{*}{13} \\
\hline & 18 & $\begin{array}{l}\text { Women can enter into } \\
\text { politics }\end{array}$ & & & & & & \\
\hline & 19 & $\begin{array}{l}\text { A woman whose job } \\
\text { involves contact with the } \\
\text { public, e.g.,teacher should } \\
\text { not continue to work } \\
\text { when she is pregnant }\end{array}$ & & & & & & \\
\hline & 20 & $\begin{array}{l}\text { In groups that have both } \\
\text { male and female } \\
\text { members, the top } \\
\text { positions should be held } \\
\text { by man }\end{array}$ & & & & & & \\
\hline & 21 & $\begin{array}{l}\text { Women should be able to } \\
\text { compete with men for } \\
\text { jobs that have } \\
\text { traditionally belonged to } \\
\text { man, such as driving }\end{array}$ & & & & & & \\
\hline & 22 & $\begin{array}{l}\text { A woman should not } \\
\text { accept a career promotion } \\
\text { if it would require her } \\
\text { family to move }\end{array}$ & & & & & & \\
\hline & 23 & $\begin{array}{l}\text { A husband should feel } \\
\text { uncomfortable if his wife }\end{array}$ & & & & & & \\
\hline
\end{tabular}




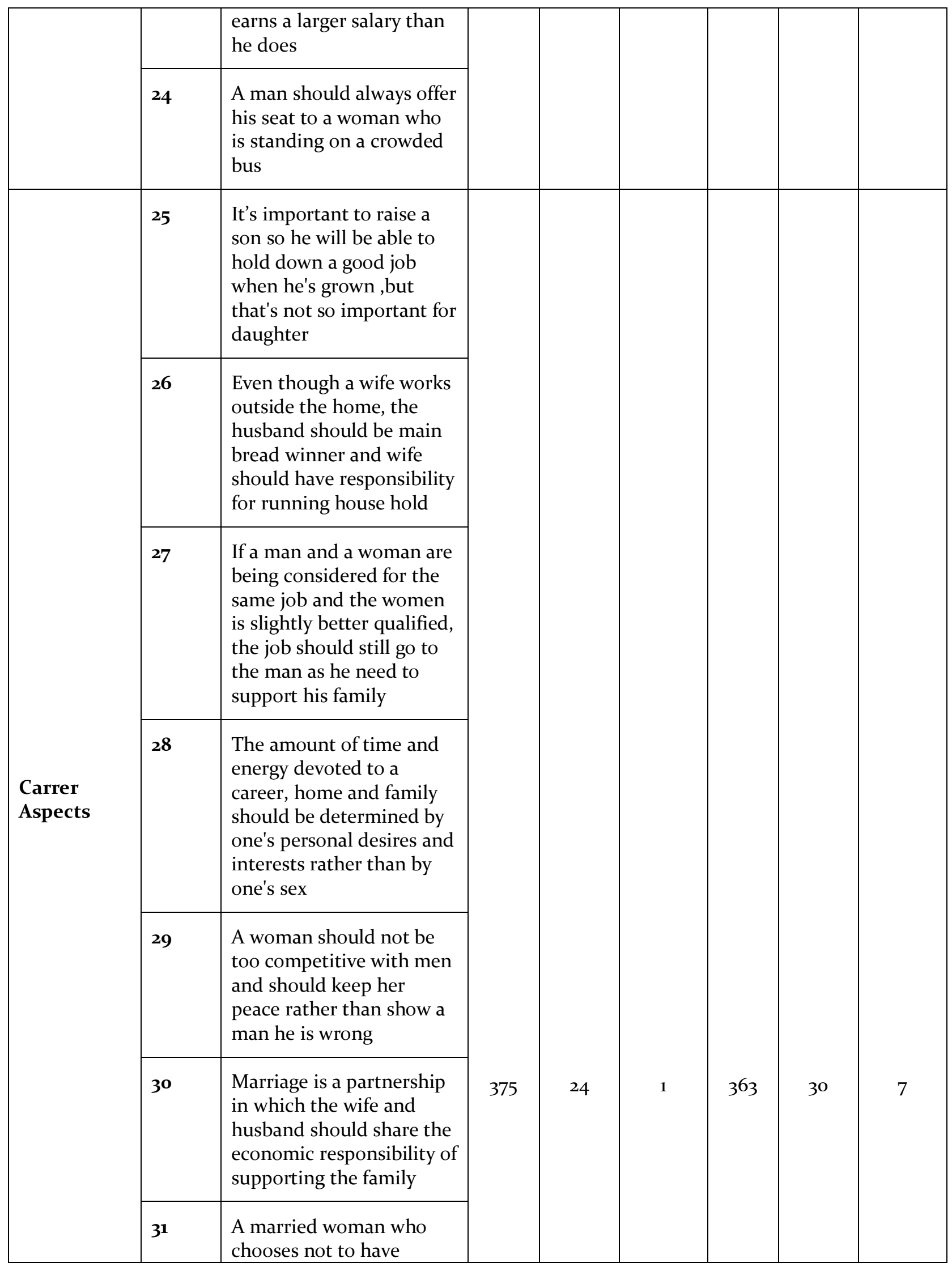




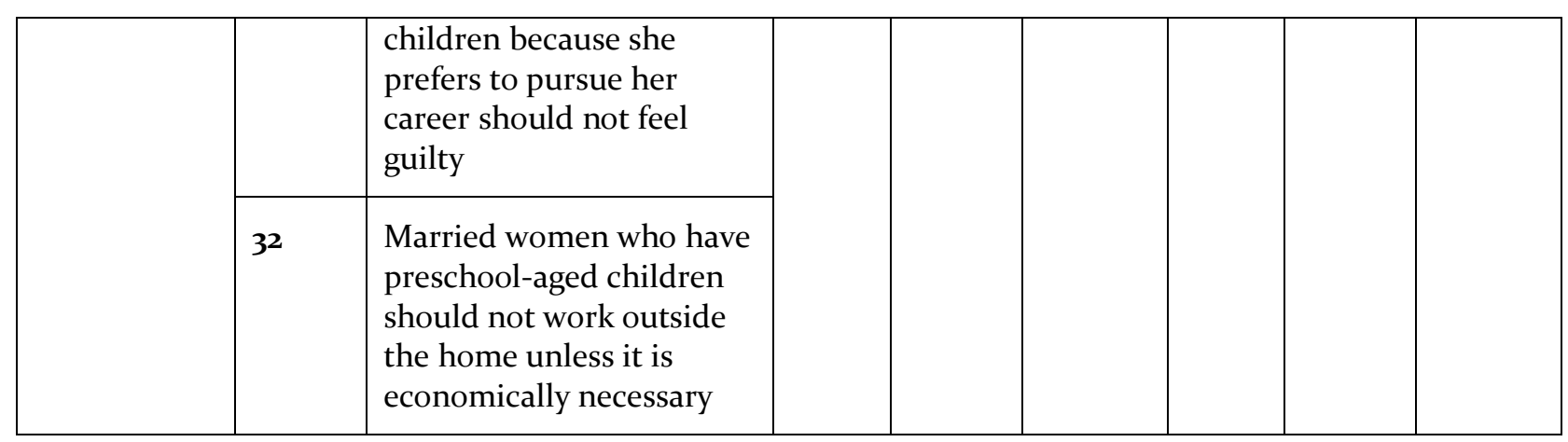

*Scores were divided into 3 categories 32-64 who opted for strongly agree, moderately agree, 96-128 who opted for Agree slightly more than disagree, disagree slightly more than agree, 160-192 who opted for Moderately disagree, strongly disagree., ${ }^{* *}$ indicates no scores

Appendix B

Gender role spouse stereotype of Group I and Group II

\begin{tabular}{|c|c|c|c|c|c|c|c|c|c|c|c|}
\hline \multirow{3}{*}{ Sl.no. } & \multirow[b]{3}{*}{ Statements (S) } & \multicolumn{5}{|c|}{ GROUP I } & \multicolumn{5}{|c|}{ GROUP II } \\
\hline & & \multicolumn{2}{|c|}{$\begin{array}{c}\text { MRS } \\
\left(\mathbf{S}_{1}-S_{5}\right)\end{array}$} & \multirow{2}{*}{$\begin{array}{l}\text { EGC } \\
3\end{array}$} & \multicolumn{2}{|c|}{$\begin{array}{c}\text { FRS } \\
\text { (S6-S8) }\end{array}$} & \multicolumn{2}{|c|}{$\begin{array}{c}\text { MRS } \\
\left(\mathrm{S}_{1}-\mathrm{S}_{5}\right)\end{array}$} & \multirow{2}{*}{$\frac{\text { EGC }}{3}$} & \multicolumn{2}{|c|}{$\begin{array}{c}\text { FRS } \\
\text { (S6-S8) }\end{array}$} \\
\hline & & $\mathbf{1}$ & 2 & & 4 & 5 & $\mathbf{1}$ & 2 & & 4 & 5 \\
\hline S1 & Mow the lawn & 284 & 100 & 16 & ** & $* *$ & 316 & 60 & 24 & $* *$ & $* *$ \\
\hline $\mathbf{S}_{2}$ & $\begin{array}{l}\text { Purchase } \\
\text { groceries }\end{array}$ & 279 & 93 & 26 & 2 & $* *$ & 300 & 70 & 30 & $* *$ & ** \\
\hline$S_{3}$ & $\begin{array}{l}\text { Handling } \\
\text { financial } \\
\text { matters }\end{array}$ & 279 & 21 & 100 & $* *$ & $* *$ & 325 & 70 & 5 & $* *$ & ** \\
\hline$S_{4}$ & $\begin{array}{l}\text { Perform basic } \\
\text { maintenance of } \\
\text { vehicles }\end{array}$ & 314 & 17 & 69 & $* *$ & $* *$ & 390 & 10 & ** & $* *$ & ** \\
\hline$S_{5}$ & $\begin{array}{l}\text { Earn most of the } \\
\text { money to } \\
\text { support the } \\
\text { family }\end{array}$ & 310 & 63 & 27 & $* *$ & $* *$ & 355 & 45 & $* *$ & $* *$ & $* *$ \\
\hline S6 & $\begin{array}{l}\text { Stay home with } \\
\text { a child who is } \\
\text { sick }\end{array}$ & 1 & 134 & 185 & 80 & 1 & $* *$ & ** & 85 & 300 & 15 \\
\hline
\end{tabular}




\begin{tabular}{|l|l|l|c|c|c|c|c|c|c|c|c|}
\hline S7 & Prepare meals & & & 92 & 182 & 126 & $* *$ & $* *$ & 15 & 315 & 70 \\
\hline S8 & $\begin{array}{l}\text { Perform } \\
\text { household } \\
\text { cleaning }\end{array}$ & 17 & 32 & 82 & 155 & 114 & $* *$ & 5 & 45 & 325 & 25 \\
\hline
\end{tabular}

${ }^{*}$ MRS= MALE ROLE STEREOTYPE, FRS= FEMALE ROLE STEREOTYPE, EGC=EGALITARIAN COUPLE, Si-S8=STATEMENT 1 TO STATEMENT $8,{ }^{* *}=$ NO RESPONSES

Nisrutha Dulla, is a Research scholar in Kalinga Institute of Industrial Technology. She has qualified in UGC-NET 2017. She is currently pursuing her Ph.d in the area of Organization Behavior. She has presented numerous papers in reputed international conferences held by IIT and NIT. She has more than five publications in peer reviewed journals.

Sugyanta Priyadarshini, is Assistant Professor in Kalinga Institute of Industrial Technology. She graduated under Utkal University and was the topper of her batch in 2014. She was the gold medalist in her master's degree from Berhampur University. Her areas of interests are Gender Economics and Health Economics. She has published more that ten articles inreputed journals, two book chapters and presented more than fifteen research ideas in international conferences. 